\title{
Business Writing: Linguistic Approach Through The Prism Of Speech Activity Theory
}

\author{
Natalia A. Sverdlova* (a), Anjela A. Kazantseva (b), Nadezhda N. Efimova (c) \\ (a), (c) Irkutsk Scientific Center SB RAS, 664033, Irkutsk (Russia), Lermontov street,nsverdlova@ yandex.ru \\ (b) Moscow City University, 129226, Moscow (Russia), 4 Vtoroy Selskohoziajstvenny proezd
}

\begin{abstract}
The format of business writing has significantly changed for the reason that each genre of written business discourse has its own strictly codified form. Expansion of communication fields including business communication domain affects the form of business discourse realization.

In this regard, to justify the hypothesis of changing previously established speech forms functioning as a business letter genre, the present paper focuses on identification and systemizing characteristics of written documents, such as structural, lexical and stylistic markers of national and cultural specificity of English written communication.

In accordance with the principles of speech activity theory and communication theory the article presents the stages of development of business contact and analyzes the structure of business writing.

In the article, the structure of the business letter is presented in compliance with the intent of the addressee. The authors propose several types of exercises aimed to enhance understanding of correlation between the addressor's intention and lexical means, as well as rubrication principles. A list of criteria for evaluating the effectiveness of written communications is also demonstrated.

Theoretical interpretation of written modus of business communication based on speech activity theory and communication theory is instrumental for the analysis of constituents of written business communication act through the prism of the addressor's communicative intentions. The approach proposed may be used in teaching practical course of the English language with the view to form universal competences of future linguists, as well as in the study of business written communication for further theoretical interpretation.
\end{abstract}

Keywords: speech activity theory; business writing; business communication; written business discourse; speech activity theory; communication theory; competences of linguists

\section{(C) 2020 Natalia A. Sverdlova, Anjela A. Kazantseva, Nadezhda N. Efimova}

This is an open access article distributed under the terms of the Creative Commons Attribution License (CC BY 4.0), which permits unrestricted use, distribution, and reproduction in any medium, provided the original author and source are credited.

Published by Kazan federal university and peer-reviewed under responsibility of IFTE-2020 (VI

International Forum on Teacher Education)

\footnotetext{
* Corresponding author. E-mail: nsverdlova@yandex.ru
} 


\section{Introduction}

The problem of teaching cross-cultural business communication is far from being solved and requires further thorough investigation. Only twenty five years ago, the very concept of business communication presumed a printed text (hard copy) - a letter, a brochure, an official letter, etc., with their register and style being highly conservative. The format of business writing as part of professional communication has significantly changed for the reason that each genre of written business discourse has its own strictly codified or arbitrary form. Expansion of communication fields including business communication domain, due to introduction and development of electronic and internet communication, affects the form of business discourse realization. «Human aspiration to effective communication is exhibited in adaptive movement towards newly acquired language reality showing in the functioning language system» (Sverdlova, 2018, p. 62), which is subject to constant change.

\section{Purpose and objectives of the study}

To justify the hypothesis of changing previously established speech forms functioning as a business letter genre, the present paper focuses on identification and systemizing characteristics of written documents (including electronic mail messages), such as structural, lexical and stylistic markers of national and cultural specificity of English written communication. Detection and systemizing of linguistic peculiarities of addressed business letters is important for formation of universal competences of higher education graduate students. The competences to be considered as defined in the Russian Federation State Educational Standards, presume implementation of business communication in oral and written forms in the national and foreign languages as well as perception of cross-cultural diversity of the society in social-historical, ethical and philosophical contexts.

\section{Literature review}

The non-literary genre is defined by Swales (1990) as a specific communicative event having one or several specific objectives. As demonstrated by the analysis of pedagogical reality, the most frequent and relevant for the professional activity of teachers-linguists are business letters with the following communicative intentions: invitation, cooperation proposal, partnership ties establishment, price-list request, job application, letter of gratitude, company presentation (Charles, 1996). Implementation of these intentions within business letter text is of particular complexity arising from the lack of «common apperception basis» of communicants, as well as from divergence of addressor's and addressee's «encyclopaedic knowledge» as prerequisites of adequate mutual understanidng.

Business letter is a specific variety of business communication with a number of distinguishing features, which characterize it as a document. «The quality of the paper reflects the quality of the company and conveys the importance of the message» (Geffner, 2000). Also it is told that business genre with the most sub-genres as a result of the diversity of spheres makes the company's professional activity (Wang, 2007). Among them are the following: specific type of information transmission, reflection of a certain professional situation, topical unity, specific graphic format and compositional structure, documentary and objective character of material presentation, extensive use of speech etiquette formulae, conciseness. 
As pointed out by many researchers, any text (including business letter) exhibits the author's thinking specificity and his/her subjective language use (Khaleyeva, 1989). In other words, a business letter acts as «tool of realization of mental content through language means» (Khaleyeva, 1989, p. 162). Consequently, the extent of correlation between addressor's and addressee's verbal and cognitive activities processes (including those professionally marked) determines success and efficiency of business cooperation as a whole.

The regularities described above reveal two significant facets of the problem under consideration: one related to the addressor, the other - to the addressee. Thus, «the mechanics of how to send the letter and when to send the letter must be decided» (Rappoport, 2008, p. 53). First, it is important that «the information introduced by the author and the structure of the document were in maximum conformity to his suppositions on the addressee's information status» (Volvak, 2002, p. 56). This thesis necessitates investigation of not only a set of linguistic and extra-linguistic means of the business letter, but also the analysis of the integral stylistic and syntactic system of this genre arising from foreign addressee's cultural specificity. Second, it needs to be born in mind that the recipient processes the information of the business letter following the pattern of the native language (English in our case).

Therefore, business letter writing is to be taught through generating an information processing algorithm, which would be analogous to that of the foreign addressee.

\section{Methodology}

It should be noted that compilation and formatting of business documents are currently undergoing certain changes: there is much more freedom of choice, location and presentation style of the details; along with standardized forma letters there appear informal messages; speech etiquette constituents are also subject to change. However, despite all the changes, the foreign author should always take into account national-cultural speech tradition and addressee's specificity in order to ensure mutual understanding and adequate impact on the recipient. You may capture your reader's attention with a hardhitting lead paragraph that goes straight to the point or offers an element of intrigue. Then, you should better hook the reader's interest: the hook is often a clear statement of the reader's problems, needs, or wants. For example, if you are writing to a colleague who had to postpone a visit, acknowledge the problem and then offer a solution. This intention is implemented via linguistic content of the business letter formal constituents.

\section{Results}

In compliance with the speech activity theory, the basic stages of business contact development are pre-contact, act of communication and post-contact. The genre under consideration may be illustrated by the very realization of the writing interaction - a communicative act comprising contact start, contact development and completion (Fig.1.). 


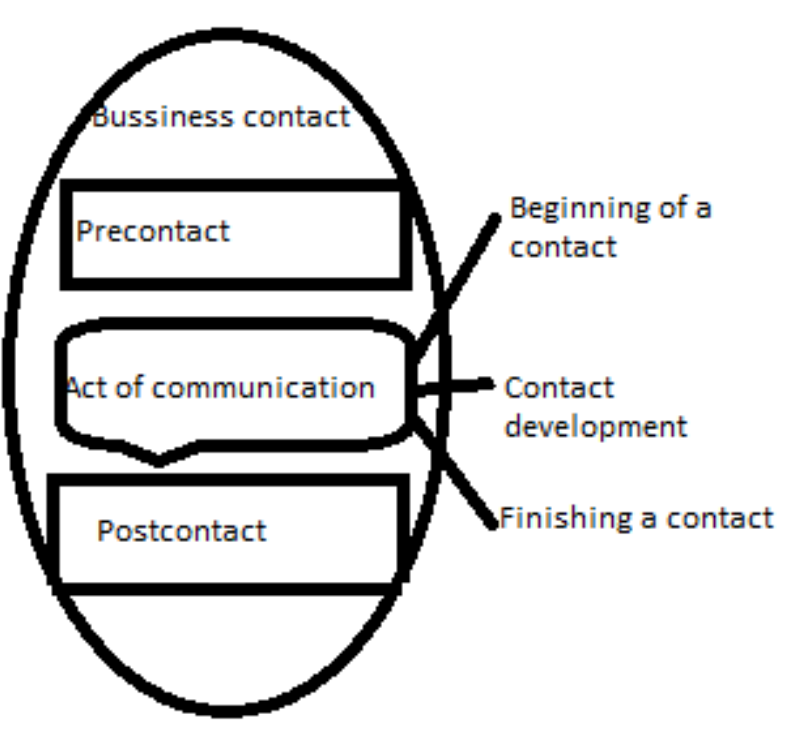

Fig.1. Business contact constituents according to the speech activity theory

It is important to note that in the analysis of the examples of realization of written interaction constituents, the most critical problem for the texts considered is that of the choice of adequate form of beginning and completion of the letter. Inadequate address may be perceived as unjustified diminution of the recipient's rights, or, vice versa, their ungrounded expansion. The final phrases are no less important than the initial ones. Completion of the letter aims to delineate professional prospects (cooperation, business partnership, joint projects, etc.). It is for this reason that the final phrases are to express hope, confidence and gratitude.

The contemporary English language possesses a variety of opening remarks, address and greeting formulae and completing phrases/complimentary closes, with the choice depending on the concrete addressee. They are characterized by high specificity and utterly pronounced focus on the addressee.

The type of realization of the language phatic function is determined solely by the addressee's status. With all the transformations (both in terms of presentation style and the extent of concretization and conciseness) occurring in the format of written business communication, the forms of official address remain almost constant, which is another proof of conservative character of this kind of discourse. We write out all the names separately, when a letter is more than one person: «Dear Mr. Layton, Mr. Thomson, and Mr. Blake». If a person's gender is unclear from a name, we write out the person's full name, dropping the title: «Dear Corey Meyer». The title of the recipient, if applicable, should be stated in the very opening phrase: «Dear Justice...». Saluting «To Whom it May Concern» is used more rarely according to some analyzed examples of letters. To express gratitude to the addressee, whose professional status is higher than that of the addressor, or an older person, the final phrase to be used is «Faithfully», «Sincerely», «Yours very truly». If the letter is written by proxy, the formula to be used is «Per. Pro» or p.p., form Latin expression «Per procurationem». If the recipient is equal in status to the addressor and has informal (probably friendly) relations with the latter, the author may use less formal phrases to express attachment and hope for further cooperation: «Best wishes», «Best regards» or «Cheers». 
A characteristic feature of business letter is the use of such a special paralinguistic means as rubrication - introduction of subject headings, which is intended to arrange the content in a more distinct fashion and to separate the parts of the letter from each other. The simplest type of rubrication is paragraphing.

Paragraphing a business letter text also contributes to clear and distinct presentation of the content, thus facilitating its perception and understanding by the addressee and allowing him/her to follow the progress of the topic discussed. This thesis is confirmed by researchers of psychology and psycholinguistics, who argue that paragraph break inevitably draws reader's attention and the content of the paragraph beginning is in a strong position reinforcing it in the reader's memory. Thus, paragraph will best highlight the part of the business letter, which is intended to draw the addressee's attention. Paragraphs surely ensure actualization of informative and perlocutive functions of communication associated with the addressor's communicative intention. Reflecting beginning, development and completion of the communicative act of written business communication paragraphs correlate with distinctly prescribed expression of the addressor's intentions (Fig.2).

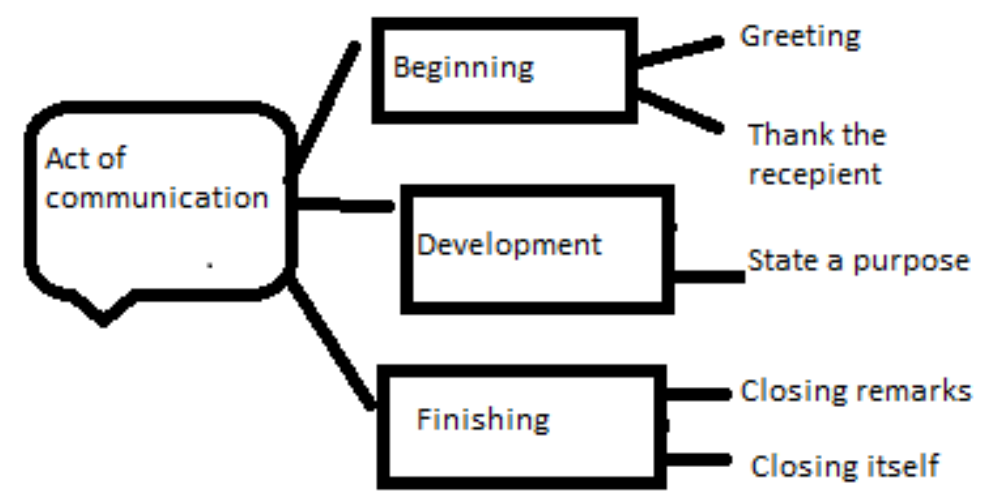

Fig.2. Division of the letter text in compliance with the addressor's communicative intention.

Among paragraphing principles to be taken into account are the following:

- each paragraph should outline and develop a single idea;

- the primary idea of the paragraph should be clearly stated in the first sentence;

- connectives within and between paragraphs should be correctly used to ensure cohesion and integrity.

Human visual perception is configured in such a way that information in the first and last lines of paragraphs is likely to catch the attention of the reader, while the middle part of the paragraph often tends to be overlooked. Therefore, less positive information should preferably be placed in the less emphasized segment of the letter.

To enhance understanding of correlation between the addressor's intention and lexical means, as well as rubrication principles, the following types of exercises can be proposed:

- $\quad$ analyze several letters differing in the degree of formality and register with the view to identify lexical, syntactic and stylistic means encoding the type of relationship between addressor and addressee; 
categorize different sections of the letter presented in an arbitrary order and put them in the right order;

choose the correct address format, opening and closing remarks based on the rank and position of the addressee;

analyze specific kinds of letters aimed to accept/refuse the proposal from the viewpoint of lexical and grammatical choices made by the addressor both to get his/her message across and to ensure politeness.

To sum up the peculiarities of business letter writing, students are provided with the list of maxims to be used as criteria for the evaluation of the letters written:

- $\quad$ preference to passive constructions will not convey the idea of you being an active person;

- $\quad$ preference to abstract words will not convince the reader in you being able to work intently on a concrete subject;

- $\quad$ use of personal syntactic structures, rather than impersonal ones, will introduce you as an active person;

- $\quad$ use of obscure lexical units and specific professional clichés will not enhance the reader's understanding;

- $\quad$ abundance of cumbersome and lengthy phrases will not convince the reader in you being dynamic;

- discrepancy between simplicity of the content and complexity of the form of your message will not contribute to better understanding;

you will not be able to get across your breakthrough innovative ideas if you fail to use adequate expressive lexical and syntactic means;

- you will not be able to emphasize the value of your solutions without describing the complexity of the problems addressed first.

It is noteworthy that these challenges may be met in a variety of ways thus contributing to the improvement of the students' skills. Some of them provide a thorough background for written speech classes and modules (e.g. «language guidance»: Thunberg, 2019), however, the related methodology falls well outside the scope of the present article.

\section{Discussions}

Since business letter is a document, it is characterized by such stylistic features as formality, precision, stereotypicity, reflecting specificity of a concrete addressee. Formality as a stylistic feature is actualized in the given type of written text through the use of certain grammatical and lexical means. Among these means reflecting orientation towards a concrete addressee, the following may be distinguished:

- $\quad$ presence of infinitive constructions emphasizing impersonal abstract-generalized character of the documents accounted for by language and speech norms of a foreign addressee. Such constructions are typical of authentic business letters; therefore, a foreign addressor should take into account the existing traditions to demonstrate respect to addressee's culture;

- use of a certain number of abbreviations, which is characteristic of the discourse of a narrow community of experts. The use of these abbreviations in business letters shows the addressor to be a member of the professional community and reflects his/her competence in the concrete domain of business communication, thus justifying his/her professional status;

- $\quad$ presence of formulae, which are reflective of the official communication style and prevail in authentic business letters. 
The use of these constructions demonstrates that the addressor has mastered the relevant professional cross-cultural communication code, which is normative for the foreign recipient, which contributes to conscious or unconscious recognition the text by the recipient. «Intercultural communicative competence should be actualized not only in favorable conditions of interaction, it also implies readiness to get out of a difficult situation caused by misunderstanding, disagreement, rejection of attitudes, different intentions of the participants in the dialogue» (Tareva \& Tarev, 2018, p.1700). A critical requirement to be met is that of precision, which presumes unambiguous interpretation by the addressee. Precision as a stylistic feature determines terminological character of the lexical means, abundance of general and specific terms, lack of connotations in general lexis.

The author's intention is implemented through the accuracy of correlation between words and context, which facilitates adequate deciphering of the business letter sense by a concrete addressee with certain status characteristics in a certain social situation.

One of characteristic features of the business letter is its stereorypicity generated by extensive use of speech clichés and meets the requirement to ensure efficient processing of the text sense by a concrete addressee. The use of clichés in the documents becomes a norm, as they are instrumental in fast and precise transmission of the information and tend to be perceived without distortions.

Among clichés there is a large amount of formulae of politeness, gratitude and respect, the choice of which depends on the recipient, his/her social status, age, individual characteristics. The most frequent examples are «Sincerely yours», «Thank you for your consideration» (a formal closing); «Very Respectfully» (often abbreviated as «V/R» is used in written and emailed correspondence between military members).

The formulae emphasizing gratitude for the attention to the information presented in the text above refer to closing remarks: «Thank you for your patience and cooperation» or «Thank you for your consideration» and then you may follow up with, «If you have any questions or concerns, don’t hesitate to let me know» and «I look forward to hearing from you».

Stereotypicity as a stylistic feature is also characterized by enhanced use of conditional mood and introductory constructions, which mitigates the categorical format of narration, thus introducing easiness in official written communication.

\section{Conclusion}

Therefore, presence of the linguistic peculiarities considered above in addressed business documents is one of addressee's system-forming factors, since they facilitate adequate perception of the content without significant losses of the sense presumed by the author.

Theoretical interpretation of written modus of business communication based on speech activity theory and communication theory is instrumental for the analysis of constituents of written business communication act through the 
prism of the addressor's communicative intentions. The above correlation of business communicative act stages and formal parts of business message is an effective basis for creation of training educational material aimed at formation of universal competences of future linguists.

\section{References}

Charles, M. (1996). Business negotiations: Interdependence between discourse and the business realationship. English for Specific Purposes, 15(1), 19-36.

Geffner, A. B. (2000). How to write better business letters. Barron's Educational Series.

Khaleyeva, I. I. (1989). Basics of the theory of foreign speech understanding training: translator training. Moscow: Vysshaya shkola.

Rappaport, B. (2008). A Shot Across the Bow: How to Write an Effective Demand Letter. Journal of the Association of Legal Writing Directors, 5, 32.

Sverdlova, N. A. (2018). The formation of bicultural bilingual through the concept of the linguistic picture of the world. In The Russian scientific and practical conference "The 25th Kudryavtsev pedagogical readings": proceedings (pp. 59-64). Irkutsk: Asprint.

Swales, M. J. (1990). Genre analysis. English in academic and research settings. Cambridge University Press: Cambridge.

Tareva, E. G., \& Tarev, B. V. (2018). Cases on intercultural communication: new approach to design. Journal of Siberian Federal University. Humanities \& Social Sciences, 11(10), 1699-1710.

Thunberg, S. (2019). Ideas in action: some reflections concerning teaching language skills to social work students. Social Work Education, 38(2), 282-286. DOI: 10.1080/02615479.2018.1515312

Volvak, N. P. (2002). Addressee's factor in public argumentative discourse (Doctoral dissertation, Vladivostok). Retrieved from https://rusneb.ru/catalog/000199_000009_002336269/

Wang, J.Y. (2007). Genre analysis on business English correspondence. Sino-Us English Teaching, 4(12), 42-47. 